\title{
Evaluation of the NMP22 BladderChek test for detecting bladder cancer: a systematic review and meta-analysis
}

\author{
Zijie Wang ${ }^{1, *}$, Hongliang Que ${ }^{1, *}$, Chuanjian Suo ${ }^{1, *}$, Zhijian Han ${ }^{1}$, Jun Tao ${ }^{1}$, Zhengkai \\ Huang ${ }^{1}$, Xiaobin Ju ${ }^{1}$, Ruoyun $\operatorname{Tan}^{1}$ and Min Gu ${ }^{1}$ \\ ${ }^{1}$ Department of Urology, The First Affiliated Hospital with Nanjing Medical University, Nanjing, 210029, China \\ *These authors contributed equally to this work
}

Correspondence to: Min Gu, email: Lancetgu@aliyun.com.cn

Ruoyun Tan, email: tanruoyun112@vip.sina.com

Keywords: bladder cancer, NMP22 BladderChek test, diagnostic, systematic review, meta-analysis

Received: June 19, $2017 \quad$ Accepted: September 03, 2017

Published: October 23, 2017

Copyright: Wang et al. This is an open-access article distributed under the terms of the Creative Commons Attribution License 3.0 (CC BY 3.0), which permits unrestricted use, distribution, and reproduction in any medium, provided the original author and source are credited.

\section{ABSTRACT}

Background: We examined the usefulness of the nuclear matrix protein 22 (NMP22) BladderChek test for detecting bladder cancer.

Materials and Methods: A literature search was performed using PubMed, Embase, the Cochrane Library, and Web of Science. The diagnostic accuracy of the NMP22 BladderChek test was evaluated via pooled sensitivity, specificity, positive likelihood ratio (PLR), negative likelihood ratio (NLR), diagnostic odds ratio (DOR), and area under curve (AUC). Inter-study heterogeneity was explored using metaregression and subgroup analyses.

Results: We included 23 studies in the systematic review and 19 in the quantitative meta-analysis. Overall sensitivity and specificity were 56\% (52-59\%) and 88\% (87-89\%), respectively; pooled PLR and NLR were 4.36 (3.02-6.29) and 0.51 (0.40-0.66), respectively; DOR was 9.29 (5.55-15.55) with an AUC of 0.8295. The mean sensitivity for $\mathrm{Ta}, \mathrm{T} 1, \geq \mathrm{T} 2$, Tis, G1, G2, and G3 disease was 13.68\%, $29.49 \%, 74.03 \%, 34.62 \%, 44.16 \%, 56.25 \%$, and $67.34 \%$, respectively.

Conclusions: The NMP22 BladderChek test shows good discrimination ability for detecting bladder cancer and a high-specificity algorithm that can be used for early detection to rule out patients with higher bladder cancer risk. It also has better potential for screening higher-grade and higher-stage tumors, and better diagnostic performance in Asians.

\section{INTRODUCTION}

Bladder cancer, commonly referred to as carcinoma of the epithelial lining of the urinary bladder, is one of most common male cancers worldwide [1]. In the United States, an estimated 54,610 men were diagnosed with a new occurrence of bladder cancer in 2013; 17,960 women were diagnosed with the malignancy in the same year [2]. The probability of developing bladder cancer sharply increases with age, from $0.02 \%$ at 39 years to $3.69 \%$ at $>70$ years [3]. Therefore, early diagnosis for people at higher risk of bladder cancer is crucial for prolonging the rate of survival and for increasing the quality of life.

In general, the modalities for early diagnosis and follow-up of bladder cancer include cystoscopy and urine cytology [4]. Cystoscopy is considered the gold standard for the initial diagnosis and staging of bladder cancer, which should be confirmed by histological examination of biopsy specimens [5]. In recent years, scientific and clinical research has intensified to identify non-invasive methods for predicting bladder cancer occurrence, such as microRNAs, bladder tumor antigen (BTA) stat, and UroVysion fluorescence in situ hybridization (FISH) [6-8]. However, these current non-invasive technologies do not accurately reflect the development and detailed information of bladder cancer, including the disease grade and stage.

Another novel assay that has been used for detecting bladder cancer is the nuclear matrix protein 22 (NMP22) test. In this test, nuclear mitotic apparatus 
protein 1 (NUMA1) levels are assessed using monoclonal antibodies [9]. Two assay formats, i.e., the NMP22 Bladder Cancer ELISA (enzyme-linked immunosorbent assay) Test Kit and the NMP22 BladderChek point-of-care (POC) test (Alere Scarborough, Inc., Waltham, MA, USA), have been approved by the US Food and Drug Administration (FDA) for bladder cancer detection and surveillance in urine samples [10]. Several diagnostic trials have explored the efficacy of the NMP22 BladderChek test in bladder cancer detection and follow-up in recent years. However, its diagnostic performance, especially its sensitivity and specificity, varied across these studies (Table 1), resulting in its diagnostic accuracy being unclear.

Accordingly, in this systematic review and metaanalysis, we comprehensively reviewed these diagnostic trials and investigated the diagnostic value of the NMP22 BladderChek test in bladder cancer detection and followup according to the PRISMA (preferred reporting items for systematic reviews and meta-analysis) guidelines.

\section{RESULTS}

\section{Study selection and characteristics}

Figure 1 shows the results of the literature searched and selected according to the PRISMA guidelines. A total 36 studies were identified from the primary literature review. Next, 28 studies were included for full-text review, and eight were excluded because they were reviews or were studies in languages other than English or Chinese. Subsequently, 23 studies [15-36] involving 8724 patients were considered eligible for the systematic review, and 19 studies involving 5291 patients were included in the meta-analysis.

Overall, 11 and 22 studies were performed in Asian populations and Caucasian populations, respectively. Most of the patients were men aged $>50$ years. Twenty and 19 studies reported total sensitivity (mean, 52.75\%) and specificity (mean, 86.37\%), respectively. All studies included in the meta-analysis used cytology or cystoscopy results as the gold standard. Figure 2 shows an overview of the methodological quality results. In general, the overall quality of the eligible studies was high.

\section{Diagnostic performance}

Sensitivity, specificity, negative likelihood ratio (NLR), and positive likelihood ratio (PLR) values and their 95\% confidence intervals (CIs) were calculated on a per-patient basis and charted on forest plots and summary receiver operating characteristic (sROC) curves (Figure 3). The overall sensitivity and specificity among the 19 studies was 56\% (52-59\%) and 88\% (87-89\%), respectively; for PLR and NLR, the pooled results were 4.36 (3.02-6.29) and 0.51 (0.40-0.66), respectively; the diagnostic odds ratio (DOR) among the studies was 9.29 (5.55-15.55) with an area under curve (AUC) of 0.83 .
With respect to bladder cancer stage and grade, Supplementary Table 1 presents the sensitivity based on histological examination. The mean sensitivity for Ta, T1, $\geq \mathrm{T} 2$, and Tis was $13.68 \%, 29.49 \%, 74.03 \%$, and $34.62 \%$, respectively; that for $\mathrm{G} 1, \mathrm{G} 2$, and $\mathrm{G} 3$ was $44.16 \%$, $56.25 \%$, and $67.34 \%$, respectively.

Significant heterogeneity was observed among the 19 studies in our meta-analysis. Accordingly, we performed meta-regression analysis to explore the origins of the heterogeneity. Figure 3 shows that the heterogeneity was suggested across the studies, and among eight factors, study quality was identified as statistically significant, indicating that the quality of the studies was responsible for the relatively high heterogeneity.

To explore the effect of ethnicity and recurrence on the diagnostic value of the NMP22 BladderChek test, we performed subgroup analysis based on ethnicity and primary occurrence/recurrence; Supplementary Figure 1 and Figure 2 show the results.

\section{Publication bias}

There was no statistically significant publication bias across the studies, the slope coefficient had a $p$-value of $0.75(-19.11,14.05)$ (Figure 4).

\section{DISCUSSION}

In this systematic review and meta-analysis, the NMP22 BladderChek test had pooled sensitivity of 56\% and specificity of $88 \%$, and pooled DOR of 9.29 and AUC of 0.83 . Moreover, the diagnostic performance increased with disease stage and grade; the test shows good discrimination ability for detecting bladder cancer among both Asians and Caucasians. To the best of our knowledge, ours is the first systematic review and meta-analysis to assess the diagnostic value of the NMP22 BladderChek test for screening bladder cancer.

The pooled DOR was 9.29 (5.55-15.55), indicating the test's relatively high discrimination ability. The pooled sensitivity and specificity was $56 \%$ and $88 \%$, respectively, suggesting the test's superior ability for ruling out patients without bladder cancer, and an inferior ability for predicting bladder cancer in higher-risk patients. Furthermore, the PLR and NLR usually reflect the diagnostic accuracy in clinical practice $[37,38]$. The PLR and NLR of the test was 4.36 and 0.51 , respectively, which shows that patients with bladder cancer have approximately 4.36 times higher possibility of testing positive compared with subjects without bladder cancer, as well as a $51 \%$ chance of an individual having bladder cancer if the test is negative. The performance of the NMP22 BladderChek test in the pooled PLR and NLR did not achieve the requirements of clinical practice, and remains to be modified for clinical confirmation and exclusion purposes. An AUC of 0.83 represents good 


\section{Table 1: Basic characteristics of eligible studies in our meta-analysis}

\begin{tabular}{|c|c|c|c|c|c|c|c|c|}
\hline Study & Ethnicity & $\begin{array}{c}\text { Case } \\
\text { number }\end{array}$ & $\begin{array}{c}\text { Mean age } \\
\text { (year; range) }\end{array}$ & Male/female & $\begin{array}{l}\text { Proportion of } \\
\text { smoking } \\
\text { patients (\%) }\end{array}$ & $\begin{array}{l}\text { Specific details of } \\
\text { index test used }\end{array}$ & $\begin{array}{c}\text { Total } \\
\text { sensitivity (\%) }\end{array}$ & $\begin{array}{c}\text { Total } \\
\text { specificity (\%) }\end{array}$ \\
\hline P.M.J. Moonen (2005) & Caucasian & 106 & $66.4(26.9-86.1)$ & $79 / 27$ & NA & NMP22BC, Cytology & $63.63 \%$ & $90 \%$ \\
\hline S. Tritschler (2006) & Asian & 100 & 67.9 & $71 / 29$ & NA & NMP22BC & $65.00 \%$ & 40 \\
\hline A. Kumar (2006) & Asian & 131 & $67(32-91)$ & $117 / 14$ & NA & NMP22BC, Cytology & $84.80 \%$ & $77.6 \%$ \\
\hline Y. Lotan (2007) & Caucasian & 1328 & $58.7(18-96)$ & $756 / 572$ & $36.1 \%$ & NMP22BC & $56.96 \%$ & $85.8 \%$ \\
\hline Y. Lotan (2008) & Caucasian & 1502 & $62.5(46-92)$ & $1175 / 327$ & $45 \%$ & NMP22BC & NA & NA \\
\hline H. Steiner (2008) & Caucasian & 183 & $60.1(36.8-83.8)$ & $123 / 60$ & $100 \%$ & $\begin{array}{l}\text { Dipstick, NMP22BC, } \\
\text { Cytology, UroVysion }\end{array}$ & $5.56 \%$ & $82.5 \%$ \\
\hline V K. Arora (2009) & Asian & 53 & $59(33-83)$ & $48 / 5$ & $66.04 \%$ & $\begin{array}{l}\text { NMP22BC, Cytology, } \\
\text { Cystoscopy }\end{array}$ & $78.95 \%$ & 80 \\
\hline H S. Choi (2009) & Asian & 1070 & 59.31 & $650 / 420$ & NA & NMP22BC & $77.50 \%$ & 88.8 \\
\hline E O. Kehinde (2011) & Asian & 178 & $55.3(16-77)$ & NA & $80 \%$ & $\begin{array}{c}\text { Cytology, NMP22BC, } \\
\text { UroVysion }\end{array}$ & $82.00 \%$ & $66.0 \%$ \\
\hline T. Smrkolj (2011) & Caucasian & 108 & 68.3 & $74 / 34$ & NA & Cytology, NMP22BC & $17.70 \%$ & $100.0 \%$ \\
\hline E C. Hwang (2011) & Asian & 1021 & 65 & $776 / 245$ & NA & NMP22BC & $22.58 \%$ & 97.97 \\
\hline L. Sagnak (2011) & Asian & 164 & 30.8 & $56 / 108$ & NA & NMP22BC & $100.00 \%$ & $85.2 \%$ \\
\hline M A. Maghrebi (2012) & Asian & 105 & $53.48(16-77)$ & $81 / 24$ & NA & NMP22BC & $61.30 \%$ & 96 \\
\hline G. Hatzichristodoulou (2012) & Caucasian & 200 & $61.3(48-75)$ & $142 / 58$ & NA & NMP22 ELISA, NMP22BC & $59.00 \%$ & $93.0 \%$ \\
\hline G. Ludecke (2012) & Caucasian & 13 & $<50$ & NA & NA & $\begin{array}{l}\text { UBC rapid, NMP22BC, BTA } \\
\text { stat }\end{array}$ & NA & NA \\
\hline E. Coskuner (2012) & Asian & 95 & $60.7(27-88)$ & $78 / 17$ & NA & NMP22BC & $44.40 \%$ & $98.4 \%$ \\
\hline P O. Sullivan (2012) & Caucasian & 475 & $69(59-77)$ & $389 / 96$ & $76 \%$ & $\begin{array}{l}\text { Cytology, microscopy, } \\
\text { NMP22BC, NMP22 ELISA }\end{array}$ & $37.70 \%$ & $96.40 \%$ \\
\hline HX. Li (2013) & Asian & 175 & $62.4(23-89)$ & $142 / 33$ & NA & LBC, FISH, NMP22BC & $67.60 \%$ & $88.1 \%$ \\
\hline R. Ritter (2013) & Caucasian & 198 & $70(20-90)$ & $151 / 47$ & NA & $\begin{array}{l}\text { UBC ELISA, Cytology, } \\
\text { NMP22BC, UBC rapid }\end{array}$ & $16.40 \%$ & $95.3 \%$ \\
\hline F A. Yafi (2014) & Caucasian & 109 & $69(33-96)$ & $90 / 19$ & $89 \%$ & $\begin{array}{c}\text { dipstick, BTA Stat, NMP22 } \\
\text { BC, ImmunoCyt }\end{array}$ & $58.00 \%$ & 85 \\
\hline L. Turkeri (2014) & Asian & 303 & 56.6 & $146 / 157$ & NA & NMP22 BC, RisikoCheck & $45.00 \%$ & $95.0 \%$ \\
\hline M D. Bell (2016) & Caucasian & 91 & $74(45-96)$ & $76 / 15$ & $89 \%$ & $\begin{array}{c}\text { Dipstick, BTA Stat, NMP22 } \\
\text { BC, ImmunoCyt }\end{array}$ & NA & NA \\
\hline Y. Lotan (2017) & Caucasian & 1016 & $20-90$ & $786 / 230$ & NA & $\begin{array}{l}\text { Cytology, NMP22 ELISA, } \\
\text { NMP22 BC, UroVysion }\end{array}$ & $11.0 \%$ & NA \\
\hline
\end{tabular}

Abbreviations: NMP22BC, NMP22 BladderChek; ELISA, Enzyme-linked immunosorbent assay; LBC, liquid-based cytology; FISH, fluorescence in situ hybridization; NA, not available.

discrimination ability for diagnosing bladder cancer $[39,40]$. Therefore, the pooled results suggest that the NMP22 BladderChek test has good discrimination ability in clinical practice and is a superior method for ruling out patients at higher risk of bladder cancer.

When tumor stage and grade were considered, the sensitivity was low for Ta tumors. However, we found that the sensitivity of the test increased steadily for identifying tumors of increasing stage, i.e., from Ta to $\mathrm{T} 1$ and $>\mathrm{T} 2$ $(13.68 \%, 29.49 \%$, and $74.03 \%$, respectively). A similar increasing trend was observed for tumor grade, where sensitivity for $\mathrm{G} 1, \mathrm{G} 2$, and $\mathrm{G} 3$ was $44.16 \%, 56.25 \%$, and 74.03 , respectively. The pooled results showed better potential for screening $>\mathrm{T} 2$ and high-grade bladder cancer. Moreover, the subgroup analysis showed that, compared with the Caucasian populations, the test had better ability to detect bladder cancer in Asian populations. Considering the increasing incidence of bladder cancer in Asian countries, the NMP22 BladderChek test should be promoted for bladder cancer detection and follow-up [41].
The heterogeneity test and meta-regression analysis showed significant heterogeneity across the included studies, and the quality of these studies may be the potential origin of the relatively high heterogeneity. The included trials involved two main types of diagnostic trials, i.e., case-control and cross-section, and the differences in patient enrollment, study design, and data collection between the two types contributed to the high heterogeneity. In an experimental model, Miyake et al. [10] investigated the potential factors influencing the NMP22 BladderChek test, and reported that the absence of significant urinary cellularity in some cases, depending on the lesion characteristics or the timing of sampling, may lead to false negative results. Therefore, these factors should be considered when exploring the potential source of heterogeneity.

We identified some weaknesses in our review. We could not investigate some influencing factors of the NMP22 BladderChek test, such as the proportions of subjects who smoked, as the included studies had limited 
published data. Second, some studies were only published as meeting abstracts, and ongoing studies may have been overlooked, which may have contributed to the publication bias detected in our study. Third, we excluded five relevant papers published in languages other than English or Chinese during the literature review and study selection, leading to potential heterogeneity. Moreover, the test has limited efficacy for detecting residual tumors before second transurethral resection of bladder cancer, which has no additional benefit when combined with cytology [42]. In the present study, we could not perform exclusive analysis with regard to this issue; therefore, our results should be interpreted with caution.

\section{MATERIALS AND METHODS}

\section{Search strategy}

We searched MEDLINE, Embase, the Cochrane Library, and Web of Science for relevant studies in all languages published from January 1, 1990, to June
1, 2017, with the following terms: (BladderChek OR NMP22BC) AND (Bladder cancer OR urinary bladder neoplasm $[\mathrm{MeSH}])$. We identified additional studies by screening the reference lists.

\section{Inclusion and exclusion criteria}

The aim of the study selection was to identify clinical studies evaluating the performance of the NMP22 BladderChek test using human urine samples. Studies were included in the systematic review and metaanalysis if they met the following inclusion criteria: (1) Clinical study comparing the diagnostic effects of the NMP22 BladderChek test with at least one measurement for patients with high bladder cancer risk; (2) provided sufficient data for constructing the diagnostic four-fold $(2 \times 2)$ contingency table; $(3)$ if data or data subsets were used in more than one article, the article with the most detail or the most recent article was chosen; (4) written in English or Chinese; (5) Related studies with unqualified data or that did not provide sufficient data were included

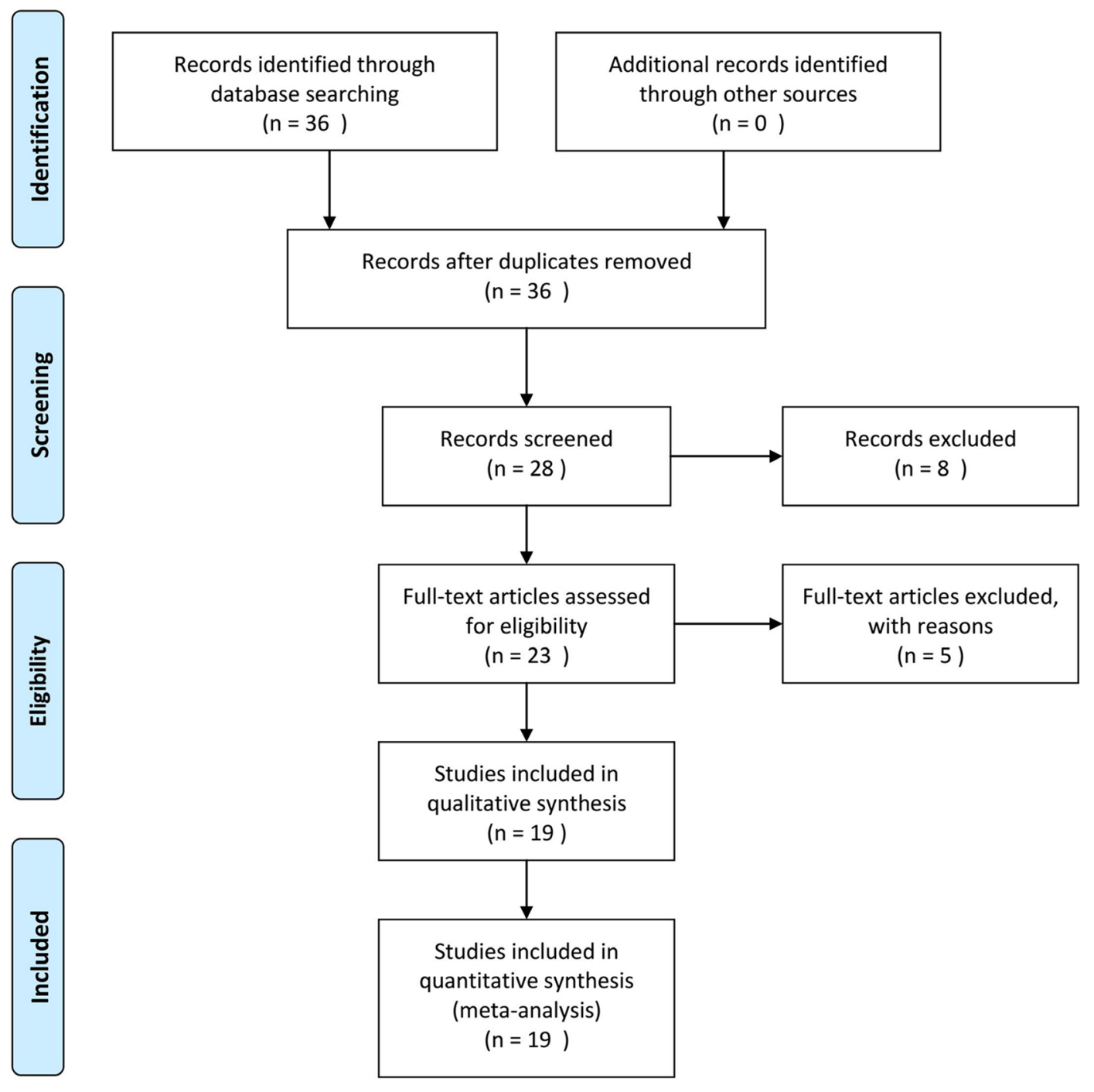

Figure 1: Flow chart for identification of eligible studies. 
only in the systematic review. The exclusion criteria were: (1) Duplicate publication; (2) reviews, case reports, letters to editors; (3) studies in languages other than English or Chinese. Two reviewers (ZJ Wang and HL Que) independently screened the collected citations for relevance and reviewed full-text articles according to the inclusion criteria. Disagreements were resolved by consultation with a third reviewer $(\mathrm{M} \mathrm{Gu})$.

\section{Data extraction and quality assessment}

Two reviewers (ZJ Wang and HL Que) extracted the relevant data independently. The retrieved data included: first author; publication year; ethnicity; number of patients; mean age; proportion of male and smoking patients; specific details of index test used; sensitivity and specificity; true positive, false positive, false negative, and true negative results; sensitivity for bladder tumor grade.
We used the Quality Assessment of Diagnostic Accuracy Studies (QUADAS-2) tool [11] to assess methodological quality. The QUADAS-2 scale contains four domains: patient selection, index test, reference standard, and flow and timing. We assessed all domains for potential risk of bias and the first three domains for concerns regarding applicability. Each question was assigned a "yes," "no," or "unclear" response when every eligible study was evaluated. A consensus reviewer (M $\mathrm{Gu}$ ) resolved any disagreement among the data extraction and quality assessment.

\section{Statistical analysis}

Meta-analysis was performed by pooling raw data on sensitivity, specificity, PLR, NLR, and DOR from the eligible studies employing the sROC curve to express the test parameter results. We assumed that sensitivity

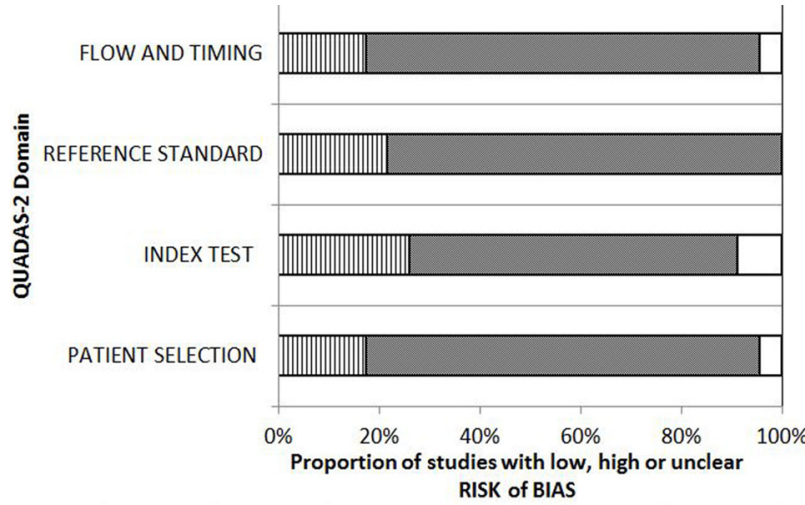

Ⓛow $\square$ High $\square$ Unclear

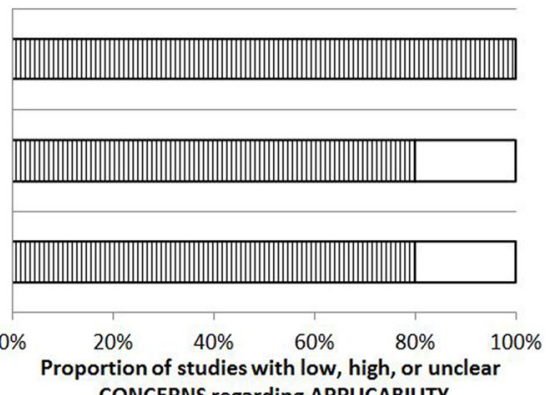

CONCERNS regarding APPLICABILITY

Figure 2: Results of QUADAS-2 quality assessment of included studies.

A

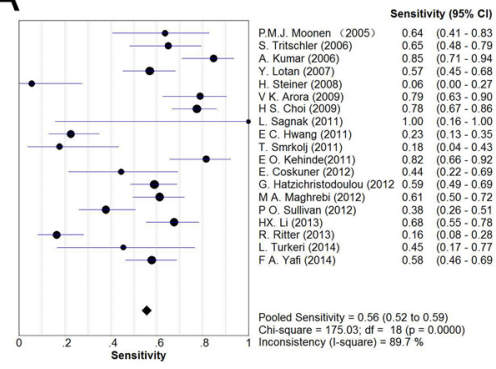

D

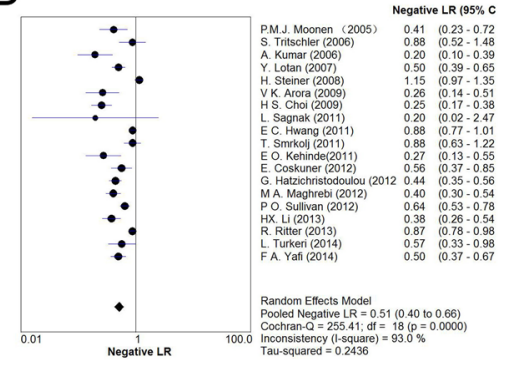

B

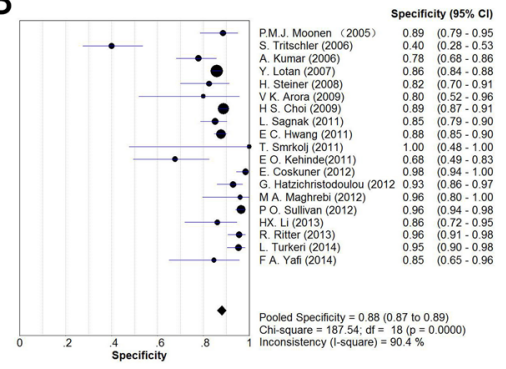

$E$

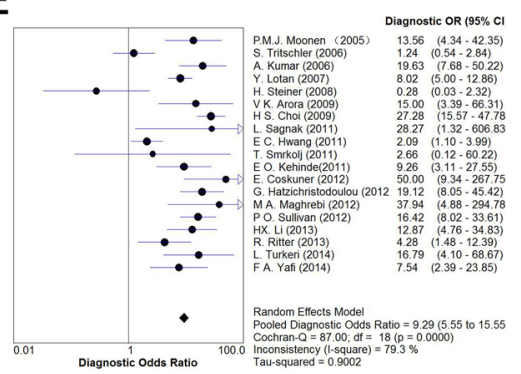

C

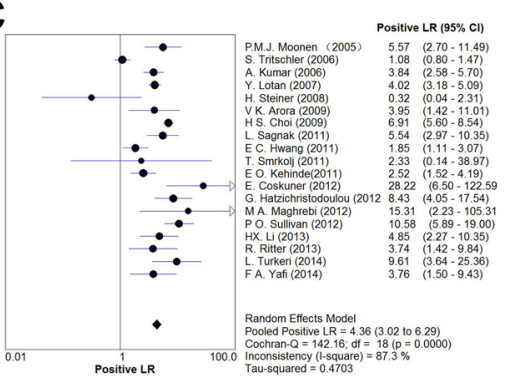

$\mathrm{F}$

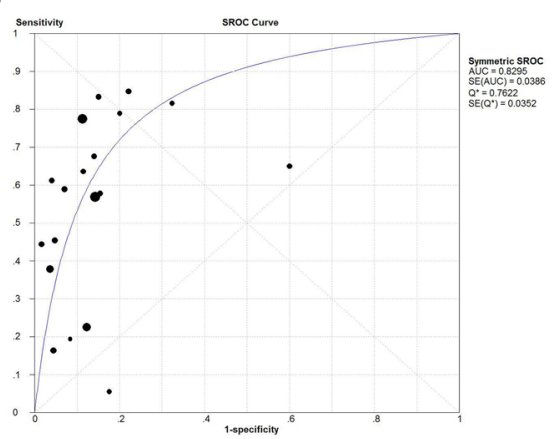

Figure 3: Meta-analysis of pooled sensitivity (A), specificity (B), PLR (C), NLR (D), DOR (E), and ROC (F). 
and specificity would vary across the studies because of differences in study populations and because of sampling errors, indicating that a random effect model should be used to account for inter-study heterogeneity. The DOR is a single indicator of test performance; a higher DOR value indicates better discriminatory test performance
[12]. AUC-ROCs are always close to 1 when tests are accurate; by contrast, tests with poor accuracy usually have AUC-ROCs approaching 0.5 [13]. Heterogeneity was assessed quantitatively using the inconsistency index $\left(\mathrm{I}^{2}\right)$, where $\mathrm{I}^{2}>50 \%$ indicated substantial heterogeneity. We calculated the Spearman correlation coefficient to

\section{Meta-Regression(Inverse Variance weights)}

\begin{tabular}{|c|c|c|c|c|c|}
\hline Var & Coeff. & Std. Err. & p - value & RDOR & [95\%CI] \\
\hline Cte. & -1.333 & 1.6785 & 0.4475 & ---- & ---- \\
\hline S & 0.415 & 0.3530 & 0.2697 & ---- & ---- \\
\hline male & 2.399 & 1.5375 & 0.1531 & 11.01 & $(0.34 ; 356.76)$ \\
\hline comparison & 1.278 & 0.8205 & 0.1538 & 3.59 & $(0.56 ; 22.97)$ \\
\hline ethnicity & -1.106 & 0.7557 & 0.1773 & 0.33 & $(0.06 ; 1.83)$ \\
\hline histological & -1.929 & 1.4741 & 0.2231 & 0.15 & $(0.01 ; 4.08)$ \\
\hline primary & 0.200 & 0.6940 & 0.7800 & 1.22 & $(0.25 ; 5.87)$ \\
\hline quality & 1.006 & 0.3969 & 0.0320 & 2.73 & $(1.11 ; 6.71)$ \\
\hline number & 1.178 & 0.9317 & 0.2379 & 3.25 & $(0.39 ; 26.72)$ \\
\hline year & 1.476 & 1.0016 & 0.1747 & 4.38 & $(0.45 ; 42.17)$ \\
\hline
\end{tabular}

Tau-squared estimate $=0.8849$ (Convergence is achieved after 10 iterations) Restricted Maximum Likelihood estimation (REML)

Figure 4: Meta-regression analysis of heterogeneity across eligible studies. Male, whether the male/female ratio $>50 \%$; comparison, whether compared with other novel diagnostic methods; ethnicity, Asian/Caucasian population; histological, whether histological examination of bladder cancer was performed; primary, whether bladder cancer recurrence was detected; quality, the quality of all included studies as assessed by QUADAS-2; number, where case number > 400; year, whether publication year was after 2011.

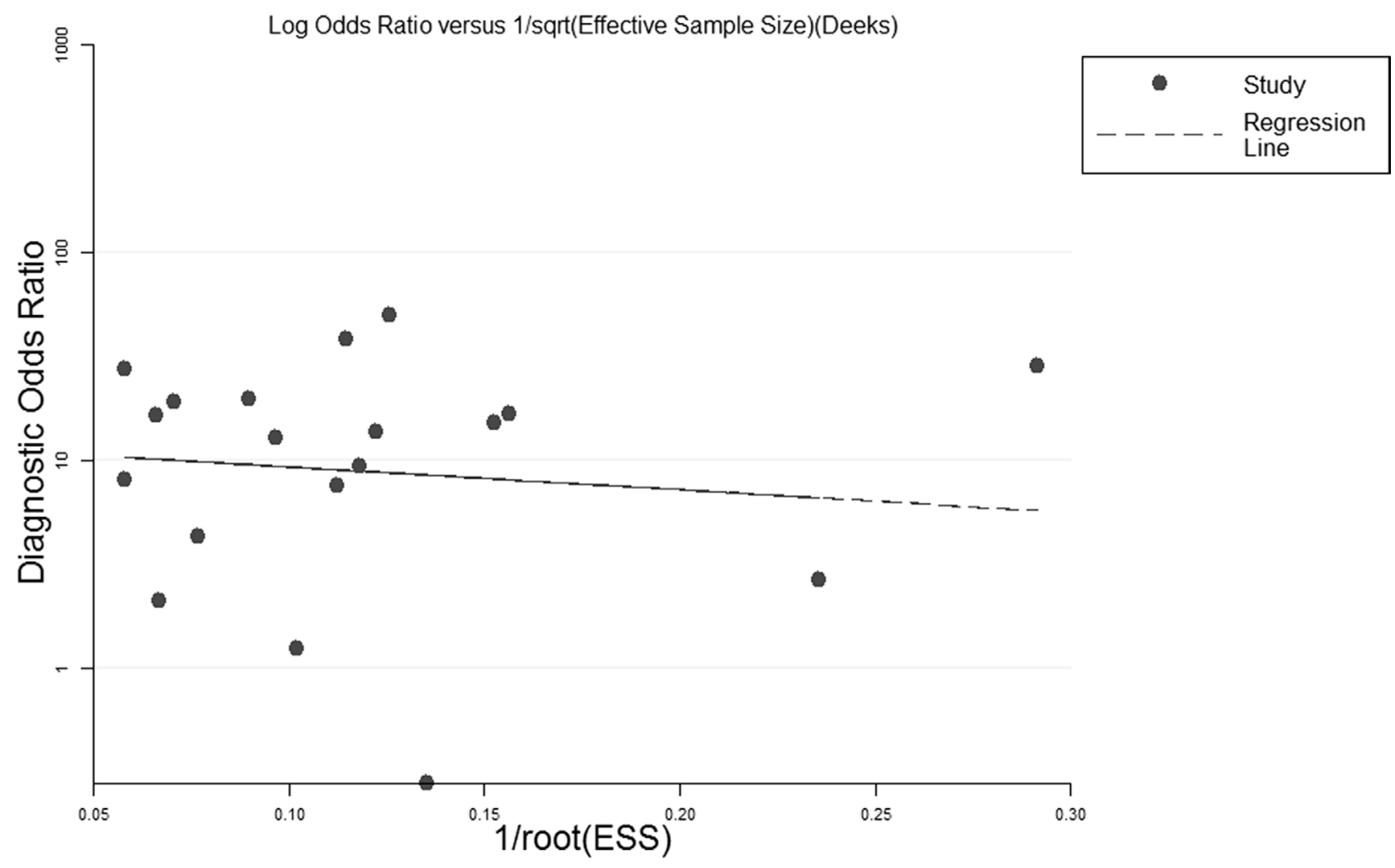

Figure 5: Deeks' funnel plot asymmetry test for studies in the systematic review. 
check the potential threshold effect. We used the Deeks funnel plot asymmetry test in the diagnostic metaanalysis to evaluate publication bias. All statistical analyses were conducted using Meta-Disc Version 1.4 software and STATA 12.0 software [14]. $P$-values $<0.05$ were considered statistically significant.

\section{CONCLUSIONS}

The NMP22 BladderChek test has good discrimination ability for detecting bladder cancer and its high-specificity algorithm can be used for early diagnostic detection to rule out patients with higher bladder cancer risk. Moreover, this test has better potential for screening tumors of higher grade and stage, and has better diagnostic performance in Asians.

\section{ACKNOWLEDGMENTS}

This work was supported by the National Natural Science Foundation of China [grant numbers 81570676, 81100532, 81470981], the Science and Education Health Project of Jiangsu Province for Important Talent [grant number RC2011055], the "333 High Level Talents Project" in Jiangsu Province, China [grant numbers BRA2015469, BRA2016514 (2015 and 2016)], the Standardized Diagnosis and Treatment Research Program of Key Diseases in Jiangsu Province, China [grant number BE2016791], the Open Project Program of Health Department of Jiangsu Province, China [grant number JSY-2-2016-099], the Jiangsu Province Six Talents Peak from Department of Human Resources, Social Security Office of Jiangsu Province, China [grant numbers 2010WSN-56, 2011WS-033], the General Program of Health Department of Jiangsu Province, China [grant number H2009907], and the Priority Academic Program Development of Jiangsu Higher Education Institutions [grant number JX10231801].

\section{CONFLICTS OF INTEREST}

The authors declare no conflicts of interest.

\section{REFERENCES}

1. Xiao F, Pu J, Wen Q, Huang Q, Zhang Q, Huang B, Huang S, Lan A, Zhang Y, Li J, Zhao D, Shen J, Wu H, et al. Association between the ERCC2 Asp312Asn polymorphism and risk of cancer. Oncotarget. 2017; 8:48488-48506. https://doi.org/10.18632/oncotarget.17290.

2. Homami A, Ghazi F. MicroRNAs as biomarkers associated with bladder cancer. Med J Islam Repub Iran. 2016; 30:475.

3. Braicu C, Cojocneanu-Petric R, Chira S, Truta A, Floares A, Petrut B, Achimas-Cadariu P, Berindan-Neagoe I. Clinical and pathological implications of miRNA in bladder cancer. Int $\mathrm{J}$ Nanomedicine. 2015; 10:791-800.
4. Zhang ML, Rosenthal DL, VandenBussche CJ. Upper urinary tract washings outperform voided urine specimens to detect upper tract high-grade urothelial carcinoma. Diagn Cytopathol. 2017; 45:700-704.

5. Ngo B, Papa N, Perera M, Bolton D, Sengupta S. Predictors of delay to cystoscopy and adequacy of investigations in patients with haematuria. BJU Int. 2017; 119:19-25.

6. Babjuk M, Oosterlinck W, Sylvester R, Kaasinen E, Böhle A, Palou-Redorta J, Rouprêt M; European Association of Urology (EAU). guidelines on non-muscle-invasive urothelial carcinoma of the bladder, the 2011 update. European urology. 2011; 59:997-1008.

7. Miyake M, Goodison S, Rizwani W, Ross S, Bart Grossman H, Rosser CJ. Urinary BTA: indicator of bladder cancer or of hematuria. World journal of urology. 2012; 30:869-73.

8. Lavery HJ, Zaharieva B, McFaddin A, Heerema N, Pohar KS. A prospective comparison of UroVysion FISH and urine cytology in bladder cancer detection. BMC Cancer. 2017; 17:247.

9. Soloway MS, Briggman V, Carpinito GA, Chodak GW, Church PA, Lamm DL, Lange P, Messing E, Pasciak RM, Reservitz GB, Rukstalis DB, Sarosdy MF, Stadler WM, et al. Use of a new tumor marker, urinary NMP22, in the detection of occult or rapidly recurring transitional cell carcinoma of the urinary tract following surgical treatment. The Journal of urology. 1996; 156:363-7.

10. Miyake M, Goodison S, Giacoia EG, Rizwani W, Ross S, Rosser CJ. Influencing factors on the NMP-22 urine assay: an experimental model. BMC urology. 2012; 12:23.

11. Whiting PF, Rutjes AW, Westwood ME, Mallett S, Deeks JJ, Reitsma JB, Leeflang MM, Sterne JA, Bossuyt PM; QUADAS-2 Group. a revised tool for the quality assessment of diagnostic accuracy studies. Ann Intern Med. 2011; 155:529-36.

12. Glas AS, Lijmer JG, Prins MH, Bonsel GJ, Bossuyt PM. The diagnostic odds ratio: a single indicator of test performance. Journal of clinical epidemiology. 2003; 56:1129-35.

13. Moses LE, Shapiro D, Littenberg B. Combining independent studies of a diagnostic test into a summary ROC curve: data-analytic approaches and some additional considerations. Statistics in medicine. 1993; 12:1293-316.

14. Zamora J, Abraira V, Muriel A, Khan K, Coomarasamy A. Meta-DiSc: a software for meta-analysis of test accuracy data. BMC medical research methodology. 2006; 6:31.

15. O'Sullivan P, Sharples K, Dalphin M, Davidson P, Gilling P, Cambridge L, Harvey J, Toro T, Giles N, Luxmanan C, Alves CF, Yoon HS, Hinder V, et al. A multigene urine test for the detection and stratification of bladder cancer in patients presenting with hematuria. The Journal of urology. 2012; 188:741-7.

16. Lotan Y, Elias K, Svatek RS, Bagrodia A, Nuss G, Moran $\mathrm{B}$, Sagalowsky AI. Bladder cancer screening in a high risk asymptomatic population using a point of care urine based protein tumor marker. The Journal of urology. 2009; 182:52-7. 
17. Lotan Y, O'Sullivan P, Raman JD, Shariat SF, Kavalieris L, Frampton C, Guilford P, Luxmanan C, Suttie J, Crist H, Scherr D, Asroff S, Goldfischer E, et al. Clinical comparison of noninvasive urine tests for ruling out recurrent urothelial carcinoma. Urologic oncology. 2017; 35:531.e15-531.e22.

18. Ludecke G, Pilatz A, Hauptmann A, Bschleipfer T, Weidner W. Comparative analysis of sensitivity to blood in the urine for urine-based point-of-care assays (UBC rapid, NMP22 BladderChek and BTA-stat) in primary diagnosis of bladder carcinoma. Interference of blood on the results of urine-based POC tests. Anticancer Res. 2012; 32:2015-8.

19. Li HX, Wang MR, Zhao H, Cao J, Li CL, Pan QJ. Comparison of fluorescence in situ hybridization, NMP22 bladderchek, and urinary liquid-based cytology in the detection of bladder urothelial carcinoma. Diagn Cytopathol. 2013; 41:852-7.

20. Kumar A, Kumar R, Gupta NP. Comparison of NMP22 BladderChek test and urine cytology for the detection of recurrent bladder cancer. Japanese journal of clinical oncology. 2006; 36:172-5.

21. Sagnak L, Ersoy H, Gucuk O, Ozok U, Topaloglu H. Diagnostic value of a urine-based tumor marker for screening lower urinary tract in low-risk patients with asymptomatic microscopic hematuria. Urol Int. 2011; 87:35-41.

22. Steiner H, Bergmeister M, Verdorfer I, Granig T, Mikuz G, Bartsch G, Stoehr B, Brunner A. Early results of bladdercancer screening in a high-risk population of heavy smokers. BJU international. 2008; 102:291-6.

23. Ritter R, Hennenlotter J, Kühs U, Hofmann U, Aufderklamm S, Blutbacher P, Deja A, Hohneder A, Gerber V, Gakis G, Stenzl A, Schwentner C, Todenhöfer T. Evaluation of a new quantitative point-of-care test platform for urine-based detection of bladder cancer. Urologic oncology. 2014; 32:337-44.

24. Turkeri L, Mangir N, Gunlusoy B, Yildirim A, Baltaci S, Kaplan M, Bozlu M, Mungan A. Identification of patients with microscopic hematuria who are at greater risk for the presence of bladder tumors using a dedicated questionnaire and point of care urine test--a study by the members of Association of Urooncology, Turkey. Asian Pac J Cancer Prev. 2014; 15:6283-6.

25. Lotan Y, Shariat SF, Group NMP22 Study Group. Impact of risk factors on the performance of the nuclear matrix protein 22 point-of-care test for bladder cancer detection. BJU international. 2008; 101:1362-7.

26. Coskuner E, Cevik I, Ozkan A, Dillioglugil O, Akdas A. In the cystoscopic follow-up of non-muscle-invasive transitional cell carcinoma, NMP-22 works for high grades, but unreliable in low grades and upper urinary tract tumors. International urology and nephrology. 2012; 44:793-8.

27. Hatzichristodoulou G, Kübler H, Schwaibold H, Wagenpfeil S, Eibauer C, Hofer C, Gschwend J, Treiber U. Nuclear matrix protein 22 for bladder cancer detection: comparative analysis of the BladderChek(R) and ELISA. Anticancer Res. 2012; 32:5093-7.
28. Smrkolj T, Mihelic M, Sedlar A, Sterle I, Osredkar J, Sedmak B. Performance of nuclear matrix protein 22 urine marker and voided urine cytology in the detection of urinary bladder tumors. Clin Chem Lab Med. 2011; 49:311-6.

29. Bell MD, Yafi FA, Brimo F, Steinberg J, Aprikian AG, Tanguay S, Kassouf W. Prognostic value of urinary cytology and other biomarkers for recurrence and progression in bladder cancer: a prospective study. World journal of urology. 2016; 34:1405-9.

30. Yafi FA, Brimo F, Steinberg J, Aprikian AG, Tanguay S, Kassouf W. Prospective analysis of sensitivity and specificity of urinary cytology and other urinary biomarkers for bladder cancer. Urologic oncology. 2015; 33:66 e25-31.

31. Moonen PM, Kiemeney LA, Witjes JA. Urinary NMP22 BladderChek test in the diagnosis of superficial bladder cancer. European urology. 2005; 48:951-6.

32. Al-Maghrebi M, Kehinde EO, Kapila K, Anim JT. Urinary survivin mRNA expression and urinary nuclear matrix protein 22 BladderChek(R) and urine cytology in the detection of transitional cell carcinoma of the bladder. Med Princ Pract. 2012; 21:295-7.

33. Hwang EC, Choi HS, Jung SI, Kwon DD, Park K, Ryu SB. Use of the NMP22 BladderChek test in the diagnosis and follow-up of urothelial cancer: a cross-sectional study. Urology. 2011; 77:154-9.

34. Arora VK, Sarungbam J, Bhatia A, Singh N, Agrawal V, Aggarwal S. Usefulness of NMP22 as an adjunct to a typical urine cytology and low-grade urothelial carcinoma. Diagn Cytopathol. 2010; 38:788-90.

35. Choi HS, Lee SI, Kim DJ, Jeong TY. Usefulness of the NMP22BladderChek Test for Screening and Follow-up of Bladder Cancer. Korean J Urol. 2010; 51:88-93.

36. Tritschler S, Scharf S, Karl A, Tilki D, Knuechel R, Hartmann A, Stief CG, Zaak D. Validation of the diagnostic value of NMP22 BladderChek test as a marker for bladder cancer by photodynamic diagnosis. European urology. 2007; 51:403-7.

37. Takeshita S, Kanai T, Kawamura Y, Yoshida Y, Nonoyama S. A comparison of the predictive validity of the combination of the neutrophil-to-lymphocyte ratio and platelet-to-lymphocyte ratio and other risk scoring systems for intravenous immunoglobulin (ivig)-resistance in Kawasaki disease. PloS one. 2017; 12:e0176957.

38. Ren X, Zhang T, Wu D, Yan T, Pang X, Du B, Lou W, Wei Q. Increased electrocatalyzed performance through high content potassium doped graphene matrix and aptamer tri infinite amplification labels strategy: Highly sensitive for matrix metalloproteinases-2 detection. Biosens Bioelectron. 2017; 94:694-700.

39. Hamza TH, Arends LR, van Houwelingen HC, Stijnen T. Multivariate random effects meta-analysis of diagnostic tests with multiple thresholds. BMC Med Res Methodol. 2009; 9:73.

40. Wu D, Wang Y, Zhang Y, Ma H, Yan T, Du B, Wei Q. Sensitive Electrochemical Immunosensor for Detection of Nuclear Matrix Protein-22 based on NH2-SAPO-34 Supported Pd/Co Nanoparticles. Scientific reports. 2016; $6: 24551$. 
41. Chen JG, Zhu J, Zhang YH, Zhang YX, Yao DF, Chen YS, Lu JH, Ding LL, Chen HZ, Zhu CY, Yang LP, Zhu YR, Qiang FL. Cancer survival in Qidong between 1972 and 2011: A population-based analysis. Mol Clin Oncol. 2017; 6:944-54.

42. Balci M, Tuncel A, Guzel O, Aslan Y, Sezgin T, Bilgin O, Senel C, Atan A. Use of the nuclear matrix protein 22 Bladder
Chek test in the diagnosis of residual urothelial cancer before a second transurethral resection of bladder cancer. International urology and nephrology. 2015; 47:473-7. 